\author{
Marquette University \\ e-Publications@Marquette
}

3-31-2012

\title{
Geometrical Considerations for the Design of Liquid-phase Biochemical Sensors Using a Cantilever's Fundamental In-plane Mode
}

\author{
L. A. Beardslee \\ Georgia Institute of Technology - Main Campus \\ Fabien Josse \\ Marquette University, fabien.josse@marquette.edu \\ Stephen M. Heinrich \\ Marquette University, stephen.heinrich@marquette.edu \\ I. Dufour \\ Université de Bordeaux \\ O. Brand \\ Georgia Institute of Technology - Main Campus
}

Follow this and additional works at: https://epublications.marquette.edu/electric_fac

Part of the Computer Engineering Commons, and the Electrical and Computer Engineering Commons

\section{Recommended Citation}

Beardslee, L. A.; Josse, Fabien; Heinrich, Stephen M.; Dufour, I.; and Brand, O., "Geometrical Considerations for the Design of Liquid-phase Biochemical Sensors Using a Cantilever's Fundamental Inplane Mode" (2012). Electrical and Computer Engineering Faculty Research and Publications. 21.

https://epublications.marquette.edu/electric_fac/21 


\title{
Geometrical Considerations for the Design of Liquid-Phase BioChemical Sensors Using a Cantilever's Fundamental In-Plane Mode
}

\author{
L.A. Beardslee \\ Department of Electrical and Computer Engineering, Georgia \\ Institute of Technology \\ Atlanta, GA \\ F. Josse \\ Department of Electrical and Computer Engineering, Marquette \\ University \\ Milwaukee, WI \\ S.M. Heinrich \\ Department of Civil and Environmental Engineering, Marquette \\ University \\ Milwaukee, WI \\ I. Dufour \\ Université de Bordeaux \\ IMS, Talence, France \\ O. Brand \\ Department of Electrical and Computer Engineering, Georgia \\ Institute of Technology \\ Atlanta, GA
}


NOT THE PUBLISHED VERSION; this is the author's final, peer-reviewed manuscript. The published version may be accessed by following the link in the citation at the bottom of the page.

\section{Abstract:}

The influence of the beam geometry on the quality factor and resonance frequency of resonant silicon cantilever beams vibrating in their fundamental in-plane flexural mode in water has been investigated. Compared to cantilevers vibrating in their first out-of-plane flexural mode, utilizing the inplane mode results in reduced damping and reduced mass loading by the surrounding fluid. Quality factors as high as 86 have been measured in water for cantilevers with a $20 \mu \mathrm{m}$ thick silicon layer. Based on the experimental data, design guidelines are established for beam dimensions that ensure maximal Q-factors and minimal mass loading by the surrounding fluid, thus improving the limit-of-detection of mass-sensitive biochemical sensors. Elementary theory is also presented to help explain the observed trends. Additional discussion focuses on the tradeoffs that exist in designing liquidphase biochemical sensors using in-plane cantilevers.

\section{Introduction}

\section{Need for microcantilever sensors}

Quantification of liquid-phase analytes is essential in biomedical and environmental sample analysis. Example applications include, but are not limited to: (1) detection of harmful water contaminants, (2) point-of-care quantification of serum proteins, (3) chemical process monitoring, and (4) studying interactions among molecules. These four examples all require that quantitative results be obtained, preferably in real time, or with short measurement times. For the most part, these analyses are currently performed by automated analytical instruments such as mass spectrometers and UV spectrophotometers. These instruments are expensive and complicated to operate, and thus are not suited to point-of-sampling use such as at a patient's bedside or for on-site monitoring of pollutants.

Microsensors have the potential to solve many of the challenges associated with the current measurement technologies, especially when quantitative measurement of a targeted set of analytes is required on-site (e.g., point-of-care applications or in situ environmental monitoring). Specifically, CMOS (complementary metal oxide semiconductor)-compatible MEMS resonators are an attractive solution for several reasons. First, they can readily be batch manufactured and fabricated using the same tooling as integrated 
circuits; this leads to reductions in cost-per-unit and also allows system-on-a-chip or system-on-a-package solutions which have a small footprint [1]. Moreover, resonators can produce a semi-digital output, which can be tracked with a digital counter, thus greatly simplifying system integration. Continuous operation of MEMS resonators in liquid is possible, and can be achieved using an approach that can be ported to a hand-held system. In addition, MEMS resonators are easily integrated with an application-specific driving/read-out circuit that can be incorporated into a system-on-apackage solution.

Because of these advantages, micromachined mass-sensitive resonant cantilevers have attracted considerable research interest. However, few studies actually operate cantilevers in liquid and continuously track the resonator's frequency. Two reasons for this are: (1) viscous damping can severely limit the resolution of cantilevers operated in liquid and (2) when operated in the traditionally utilized fundamental out-of-plane flexural mode, there is a significant amount of mass-loading by the surrounding liquid as evidenced by the frequency shift when the devices are immersed in liquid. This leads to a higher starting mass and thus lower mass sensitivity [2] and [3]. In this work, cantilevers utilizing the fundamental in-plane flexural mode are characterized in liquid and the quality factor and frequency shift due to fluid loading are measured. The experimental data are then combined with FEM (finite element method) simulations of the chemical sensor sensitivity to determine the optimal sensor geometry (of the tested devices) for creating gravimetric liquid-phase sensors.

\section{Previous cantilever characterization and sensor work}

In sensing applications in which cantilever dynamic-mode operation is used, the short-term frequency stability limits the sensor resolution. The frequency stability is correlated with the quality factor, $Q$, of the resonance mode. For this reason, several recent studies have measured and modeled the $Q$-factors of cantilevers vibrating in out-ofplane bending modes in air [4], [5], [6], [7] and [8]. While $Q$-factors up to 1500 have been measured for the first out-of-plane bending mode in air [4], liquid operation becomes challenging because of the substantial viscous damping by the fluid. Besides low $Q$-factors, typically not exceeding 10-20 in water [2], a substantial reduction of

Sensors and Actuators B: Chemical, Vol. 164, No. 1 (March 2012): pg. 7-14. DOI. This article is @ Elsevier and permission has been granted for this version to appear in e-Publications@Marquette. Elsevier does not grant permission for this article to be further copied/distributed or hosted elsewhere without the express permission from Elsevier. 
the out-of-plane resonance frequency (typically in the range of 30$50 \%$ ) is observed in liquid due to the large effective mass of the fluid. In addition, cantilevers that push against the fluid are more sensitive to viscosity and density changes in the liquid itself [2], which can be detrimental in identifying frequency shifts due to the sorption of analyte molecules from the liquid.

Few systematic studies of cantilever-based sensors operated in the liquid-phase exist, mostly because the surrounding fluid severely damps the cantilever response, thus limiting sensor resolution. Often the chosen sensing strategy is to measure a baseline sensor output in air (i.e., resonant frequency, piezoresistor resistance, etc.), expose the sensor surface to liquid-phase analytes, which are sorbed by a sensitive layer on the device's surface, and then dry the sensor and remeasure its characteristics in air [9]. This strategy can be problematic in practical applications because a washing step is required which necessitates additional reagents. Additionally, particles can contaminate the device surface during the drying step. Furthermore, the measurement process, including device drying, is generally not appropriate for real-time or in situ measurements. Despite these challenges this strategy has been used to achieve $\mathrm{ng} / \mathrm{ml}$ limits of detection for cancer biomarkers in liquid [10].

Optical detection of resonance modes has been employed to allow for continuous tracking of a cantilever's resonant frequency during liquid-phase operation [11]. Generally, optical strategies require off-chip components that are incompatible with integrated systems. However, very recently, cantilever resonators with integrated optical detection components have been used to demonstrate $\mathrm{ng} / \mathrm{ml}$ range limits of detection for hepatitis virus in solution [12]. For continuous resonator operation in liquid using a fully integrated excitation and read-out strategy, Vancura et al. investigated cantilevers operated in their first out-of-plane flexural mode as resonant chemical sensors [2]. These devices are CMOS-compatible and use a magnetic excitation mechanism and piezoresistive detection scheme to achieve limits of detection in the parts-per-million (ppm) range for volatile organic compounds in water [2]. Microdisk resonators supported by a clamped-clamped beam and utilizing thermal actuation and piezoresistive detection are a second example of a CMOS-compatible strategy that has been used to make liquid-phase 
sensors [13]. Toa et al. investigated a novel clamped-free cantilever structure for liquid-phase biosensors, with reported quality factors in the range of 14 in water [14]. The authors of [14] also measure a $Q$ factor of 249 in water (for an identical device) using a closed-loop measurement setup. However, to fairly compare the reported data, only open-loop characteristics should be considered. Direct resonator operation in liquid has also been demonstrated for sensors detecting heavy metals, whereby the metal ions are plated onto a masssensitive resonator, thereby altering its mass and thus the resonance frequency [15]. The same investigators have also demonstrated silicon resonator operation in water yielding $Q$-factors on the order of a few hundred [16]. Unfortunately, these high- $Q$ devices consume large amounts of power and have a large temperature rise across their surface, which may be problematic for ligands used in biochemical sensing. A final example of resonator operation in fluid is the use of piezoresistive cantilevers for mass-sensitive detection of ethanol [17].

A promising alternative strategy for liquid-phase sensing using cantilevers has been presented in [18]. In this work, a fluid channel is routed through the interior of the cantilever itself, which allows the beam to operate in air or even vacuum with quality factors as high as 15,000 , and thus mitigating the damping problem in fluids. This strategy makes extremely low limits of detection possible and quantities as small as a single particle or cell have been measured using this approach. Although the embedded fluid channel resonator offers single molecule resolution, it currently requires a complex fabrication process and can only be used with relatively low fluid flow rates (on the order of $1 \mu \mathrm{l} / \mathrm{min}$ at 10 bar of pressure). A piezoresistive read-out scheme has recently been demonstrated for the embedded fluid channel devices [19]. A similar method for $Q$ enhancement has also been demonstrated using flexural plate resonators [20]. Finally, cantilever quality factors during liquid operation have been improved by placing the cantilever in a flow cell where only one side of the device is immersed, thus reducing the amount of energy loss to the fluid [21]. This strategy yields $Q$-factors in the hundreds, but ensuring that the flow pattern is maintained without wetting the cantilever may be difficult in embedded applications.

Sensors and Actuators B: Chemical, Vol. 164, No. 1 (March 2012): pg. 7-14. DOI. This article is (C) Elsevier and permission has been granted for this version to appear in e-Publications@Marquette. Elsevier does not grant permission for this article to be further copied/distributed or hosted elsewhere without the express permission from Elsevier. 


\section{Figures of merit}

Conventionally, the limit of detection (in ppm) of a masssensitive chemical sensor is defined as three times the noiseequivalent analyte concentration, which itself is given by the ratio of the short-term frequency stability $\Delta f_{\min }$ (in $\mathrm{Hz}$ ) determined e.g. via the Allan variance method and the chemical sensor sensitivity $S$ (in $\mathrm{Hz} / \mathrm{ppm})$ :

$$
\mathrm{LOD}=3 \frac{\Delta \mathrm{f}_{\min }}{\mathrm{S}}
$$

The achievable sensitivity depends on the sorption characteristics of the enrichment membrane (or ligand in the case of biosensing) coated onto the sensor surface, which is specific to a particular analyte, and on the gravimetric sensitivity of the resonant microsensor. Alternatively, the LOD might be expressed as three times the ratio of the relative frequency stability $\sigma_{\min }$ to the relative chemical sensor sensitivity $S_{R}$ :

$$
\mathrm{LOD}=3 \frac{\sigma_{\min }}{\mathrm{S}_{\mathrm{R}}}=3 \frac{\Delta \mathrm{f}_{\min } / \mathrm{f}}{\mathrm{S} / \mathrm{f}}
$$

As described in [22], the chemical sensitivity $S$ (or relative chemical sensitivity $S_{R}$ ) may be written as the product of the gravimetric sensitivity $G$ (or the relative gravimetric sensitivity $G_{R}$ ) of the coated resonant sensor, i.e., the absolute or relative change in frequency $f$ due to a change in coating density $\rho_{\mathrm{m}}$, and the analyte sensitivity $S_{\mathrm{A}}$, i.e., the change in coating density $\rho_{\mathrm{m}}$ due to a change in analyte concentration $c_{\mathrm{A}}$ in the surrounding medium:

$$
\mathrm{S}=\mathrm{G} \cdot \mathrm{S}_{\mathrm{A}}=\frac{\partial \hat{\partial} \rho_{\mathrm{m}}}{\partial \rho_{\mathrm{m}} \partial \mathrm{c}_{\mathrm{A}}}, \mathrm{S}_{\mathrm{R}}=\mathrm{G}_{\mathrm{R}} \cdot \mathrm{S}_{\mathrm{A}}=\left(\frac{1}{\mathrm{f}} \frac{\partial \mathrm{f}}{\partial \rho_{\mathrm{m}}}\right) \frac{\partial \mathrm{p}_{\mathrm{m}}}{\partial \mathrm{c}_{\mathrm{A}}}
$$

If the analyte concentration is given in $\mathrm{ppm}(\mathrm{v} / \mathrm{v})$, the analyte sensitivity $S_{A}$ may be calculated as:

Sensors and Actuators B: Chemical, Vol. 164, No. 1 (March 2012): pg. 7-14. DOI. This article is (C) Elsevier and permission has been granted for this version to appear in e-Publications@Marquette. Elsevier does not grant permission for this article to be further copied/distributed or hosted elsewhere without the express permission from Elsevier. 
NOT THE PUBLISHED VERSION; this is the author's final, peer-reviewed manuscript. The published version may be accessed by following the link in the citation at the bottom of the page.

$$
\mathrm{S}_{\mathrm{A}}=\frac{\partial \rho_{\mathrm{m}}}{\partial \mathrm{c}_{\mathrm{A}}}=\rho_{\mathrm{A}} \cdot \mathrm{K} \cdot 10^{-6}
$$

where $\rho_{\mathrm{A}}$ is the density of the analyte absorbed into the sensitive layer, and $K$ is the partition coefficient of the particular analyte/membrane combination, i.e., the ratio of the analyte concentration in the sensitive film to the analyte concentration in the surrounding matrix. The factor $10^{-6}$ accounts for the fact that $c_{\mathrm{A}}$ is given in ppm.

The sensor's limit of detection as defined by Eq. (1) is particularly affected by the geometrical dependence of the minimal detectable frequency change $\Delta f_{\min }$, a quantity that is generally improved (i.e., reduced) by increasing the quality factor of the resonance. This fact provides the main motivation behind investigating in-plane rather than out-of-plane cantilever modes. In addition, as stated earlier, utilizing the in-plane mode (in comparison to the fundamental out-of-plane mode) gives much lower mass-loading due to the surrounding fluid which helps to reduce the cantilever's starting mass and thus improves the mass-sensitivity [3].

Mechanical characterization of cantilevers with twenty different length and width combinations and four different thicknesses (eighty devices in total) have been performed. The equations above in combination with FEM modeling to simulate the gravimetric sensitivity allows one to estimate which cantilever would give the lowest detection limits (at least for those beams tested), if used as a liquidphase biochemical sensor. More broadly, examination of the characterization data allows one to examine the tradeoffs that exist in the design of biochemical sensors using in-plane cantilevers.

\section{Measurement protocol}

In order to investigate the effect of beam dimensions on the resonance frequency and quality factor of cantilevers operated in their first in-plane flexural mode, thermally actuated and piezoresistively detected single-crystal silicon cantilevers (see Fig. 1) were fabricated using a bulk-micromachining process that has been previously presented [13]. For protection of the aluminum metal lines during

Sensors and Actuators B: Chemical, Vol. 164, No. 1 (March 2012): pg. 7-14. DOI. This article is (C) Elsevier and permission has been granted for this version to appear in e-Publications@Marquette. Elsevier does not grant permission for this article to be further copied/distributed or hosted elsewhere without the express permission from Elsevier. 
liquid testing a stack of PECVD (plasma enhanced chemical vapor deposition) oxide/nitride layers were used. (See Fig. 2 for a diagram of the beam cross section.) The total target thickness of the PECVD passivation layers was $1.2 \mu \mathrm{m}$. Silicon thickness measurements were done at a $90^{\circ}$ angle in a Hitachi 3500 SEM. The silicon could be differentiated from the dielectric layers because it does not charge and also because its sidewalls are scalloped from etching using the $\mathrm{BOSCH}$ process.

The devices were packaged using acrylic manifolds as presented in [23]. It was determined that the pressure from the top manifold used for fluid injection could slightly alter the beam's resonant frequency. Consequently, the top manifold was not used during mechanical characterization in liquid. In addition, leaving the package open to the air allows one to ensure that there are no air bubbles trapped next to the cantilevers, which could lead to inaccurate results. The amplitude of the observed signal provides further confirmation that there is no air trapped beneath the resonator.

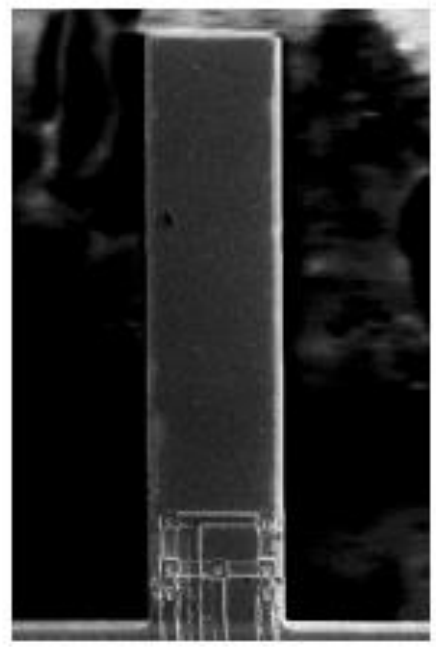

Figure 1: SEM image of a fabricated $45 \mu \mathrm{m}$ wide and $200 \mu \mathrm{m}$ long cantilever. The Wheatstone bridge and excitation resistors are visible at the base of the device. 




Figure 2: Cross section of the tested cantilevers. Note that thickness values given in the text of the paper are those of the silicon layer only and do not include the thermal oxide or PECVD passivation layers.

Cantilever mechanical characterization was performed in deionized water. For testing in liquid a drop of water was placed inside the acrylic ring (which was glued to the surface of the die for testing) [23] and allowed to percolate through the bulk-micromachined opening. Subsequently, the amplitude and phase response from the piezoresistive Wheatstone bridge [13] was captured using an Agilent 4395A network/spectrum analyzer. For measurement in liquid a Wheatstone bridge bias voltage of $3 \mathrm{~V}$ was used. A single heating resistor was driven with an approx. 2.2 $\mathrm{V}_{\mathrm{pp}} \mathrm{AC}$ excitation voltage superimposed on a $3 \mathrm{~V}$ bias voltage [23]. In some cases, slightly higher voltages ( $D C$ and $A C$ ) were needed to produce a discernible output signal. Typical resistance values for both the heating resistors and the piezoresistors were 500-700 $\Omega$. After measurement, the capacitive signal crosstalk between input and output signals was removed using Nyquist's method [24]. The quality factor and resonant frequency were calculated using the 3-dB method in MATLAB (Mathworks, Natick, MA).

\section{Results and discussion}

The measured frequency transfer characteristics of the fundamental in-plane flexural mode for a $200 \mu \mathrm{m}$ long, $45 \mu \mathrm{m}$ wide, and $8 \mu \mathrm{m}$ thick cantilever operated in air and in water are given in Fig. 3. The frequency characteristics show the expected behavior for a second-order system. In air, the fundamental in-plane resonance 
frequency is $1212 \mathrm{kHz}$ with a $Q$-factor of 2140 ; in water, the frequency drops by only $6.5 \%$ to $1133 \mathrm{kHz}$ with a $Q$-factor of 44 (determined from the 3-dB width of the amplitude transfer characteristic). While the $Q$-factor is reduced by a factor of 78 by immersing the cantilever in water, its value in water is larger than those typically obtained for cantilevers vibrating in their out-of-plane rather than in-plane flexural mode.

Even in air, the measured resonant frequency (Fig. 3) is lower than that predicted by simple beam bending theory without fluid effects, i.e., $f_{0}=0.1615\left(b / L^{2}\right) \sqrt{E / \rho_{b}}$, where $E$ and $\rho_{\mathrm{b}}$ are the Young's modulus and mass-density of the beam material, $b$ is the width of the beam and $L$ is the length of the beam. The difference can be attributed to three effects: (1) the viscous damping and mass loading from the fluid being dragged along with the beam as it vibrates, (2) the nonideal boundary condition comprising a compliant silicon support structure with a silicon "rim" that results from misalignment and under-etching during the bulk micromachining fabrication process, and (3) the presence of shear deformation and rotational inertia effects ("Timoshenko beam effects"), particularly in the short and wide cantilevers.
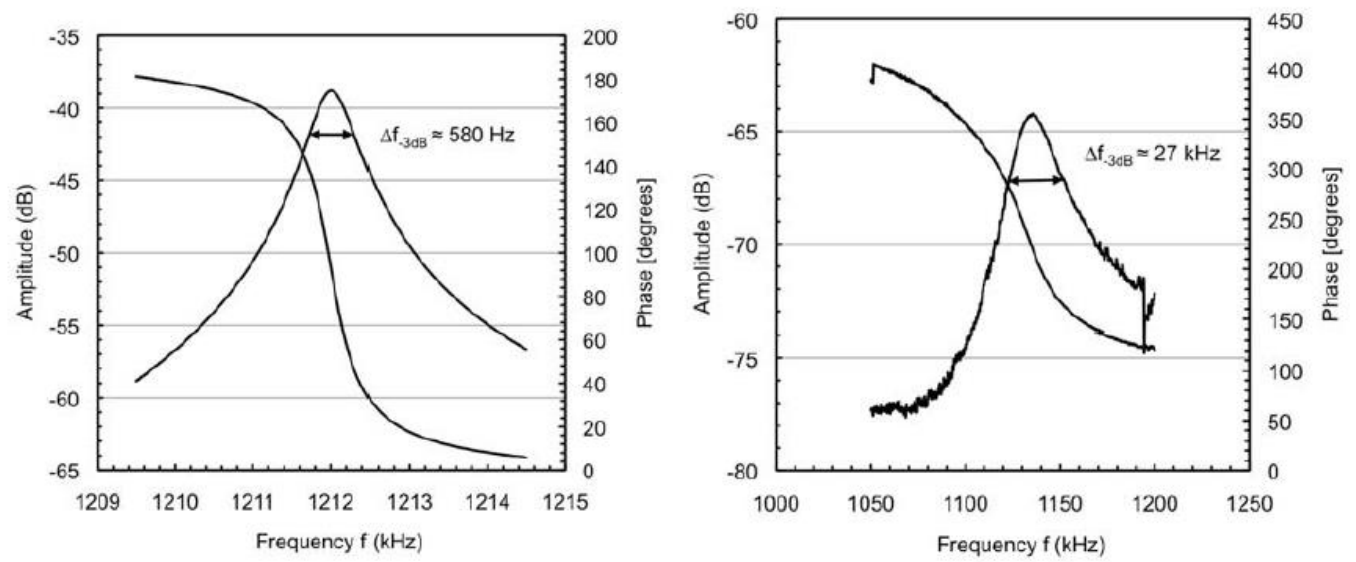

Figure 3: Amplitude and phase transfer characteristic for a $45 \square \mathrm{m}$ wide, $200 \mathrm{~m}$ long and $8 \mathrm{~m}$ thick cantilever in air (left) and in water (right).

Fig. 4 summarizes the quality factor in liquid for all cantilever sizes tested. For a given device thickness, the $Q$-factor increases proportional to the square root of the resonant frequency, i.e., 
proportional to $b^{1 / 2} / L$, as is predicted by the following theoretical result, which is based on the assumptions that viscous damping by the surrounding fluid is the dominating loss mechanism and that compliant support and Timoshenko beam effects are neglected [25] and [26]:

$$
Q \approx 0.7124\left(E \rho_{b}^{3} / \eta^{2} \rho_{f}^{2}\right)^{1 / 4}\left(h b^{1 / 2} / L\right)
$$

where $\eta$ and $\rho_{\mathrm{f}}$ are the dynamic viscosity and density of the fluid respectively. Furthermore, for a constant in-plane resonance frequency (i.e., constant in-plane cantilever geometry), the $Q$-factor increases with increasing device thickness, again as expected from the theoretical result above [25] and [26]. The highest $Q$-factor of 86 was measured for a $200 \mu \mathrm{m}$ long, $75 \mu \mathrm{m}$ wide and $20 \mu \mathrm{m}$ thick cantilever. In general, short, wide and thick cantilevers yield the highest $Q$-factors for the flexural in-plane mode in water.

Fig. 5 shows the observed frequency shift when immersing the cantilevers in water as a percentage of the resonant frequency in air for all tested cantilevers as a function of $L / b^{1 / 2}$, which is - to first order - inversely proportional to the square root of the resonance frequency in air. The air measurements were done with a $3 \mathrm{~V}$ Wheatstone bridge bias, a $0.5 \mathrm{~V} \mathrm{DC}$ bias and a $0.7 \mathrm{~V}_{\mathrm{pp}} \mathrm{AC}$ signal applied to the heating resistors. While there appears to be a general trend of reduced mass loading for higher-frequency devices (i.e., smaller $L / b^{1 / 2}$ ratio), the mass loading by the surrounding fluid will be discussed in more detail in the following. 
NOT THE PUBLISHED VERSION; this is the author's final, peer-reviewed manuscript. The published version may be accessed by following the link in the citation at the bottom of the page.



Figure 4: Q-factor of in-plane bending mode for cantilevers with 5, 8, 12 and 20 $\mu \mathrm{m}$ silicon thickness in water as a function of b1/2/L (square root of beam width divided by length), which is - to first order - proportional to the square root of the resonance frequency. (Lines are linear fits of the data for a given device thickness.)

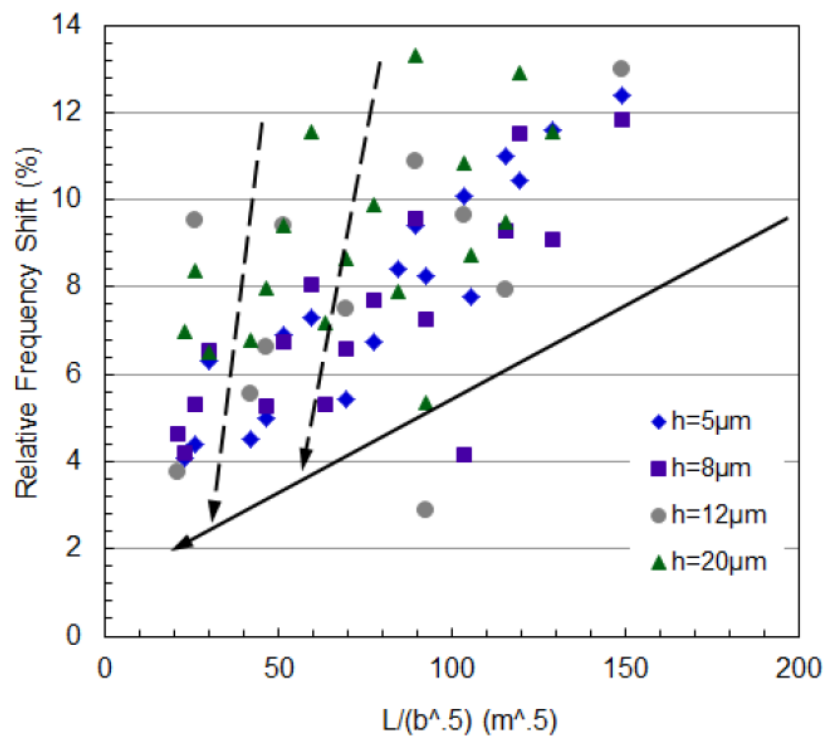

Figure 5: Relative frequency shift of the first in-plane flexural mode when immersed in water (compared to its value in air) as a function of cantilever length divided by the square root of the cantilever width for cantilevers with silicon thicknesses of $5,8,12$ and $20 \mu \mathrm{m}$. The solid arrow indicates the overall trend of a reduced frequency shift with decreasing $\mathrm{L} / \mathrm{b} 1 / 2$ ratio, i.e. increasing resonance 
NOT THE PUBLISHED VERSION; this is the author's final, peer-reviewed manuscript. The published version may be accessed by following the link in the citation at the bottom of the page.

frequency. The dashed arrows show the trend for a given cantilever length (in this case 200 and $400 \mu \mathrm{m})$, where the frequency shift rapidly decreases with increasing beam width (see also Fig. 6).



Figure 6: Percentage frequency shift of the first in-plane flexural mode when immersed in water (compared to value in air) as a function of the cantilever length divided by the square root of the cantilever width for different lateral (in-plane) dimensions $(b, L)$ of cantilevers with an $8 \mu \mathrm{m}$ silicon thickness.



Figure 7: Percentage frequency shift of the first in-plane flexural mode when immersed in water (compared to value in air) as a function of the cantilever length 
divided by the square root of the cantilever width for cantilevers with a length of 400 $\mu \mathrm{m}$.

Fig. 6 and Fig. 7 represent subsets of the data shown in Fig. 5. While Fig. 6 shows data for cantilevers with a silicon thickness of $8 \mu \mathrm{m}$ (grouped by cantilever length), Fig. 7 summarizes the observed frequency shift for $400 \mu \mathrm{m}$ long cantilevers (grouped by cantilever thickness). One can see from Fig. 6 and Fig. 7 that - for a given cantilever length (and thickness) - the frequency shifts are approximately linear when plotted against $L / b^{1 / 2}$; this is what is expected from theoretical models [26]. Overall, the experimental data show that short, wide and thin cantilevers exhibit the smallest frequency shift when immersed in water, i.e., the smallest added fluid mass. Put differently, as the cantilevers get wider and shorter their resonance frequency increases, thus as the cantilever resonance frequency increases the amount of mass loading from the surrounding fluid decreases.

While the $Q$-factor affects the short-term frequency stability and thus the sensor resolution (see Eq. (1)), the frequency shift due to mass loading by the surrounding liquid is also an important consideration because it affects the sensor sensitivity. Assuming that the resonance frequency is proportional to the square root of the effective stiffness-to-mass ratio for the particular resonant mode, the frequency change due to mass binding of a target substance on the surface of a gravimetric sensor is given by [3]:

$$
\Delta f=\frac{1}{2} \frac{\Delta m}{m} f_{0}
$$

where $\Delta f$ is the observed frequency decrease due to the additional mass, $\Delta m$ is the (effective) added mass associated with the target substance, $m$ is the original effective mass of the resonator, and $f_{0}$ is the original resonance frequency of the device (prior to mass uptake). One can see that having a lower starting mass improves (increases) the observed frequency shift due to a given mass change from the analyte that one wishes to detect. Thus, minimizing the mass loading on the beam by the surrounding fluid is important and is one

Sensors and Actuators B: Chemical, Vol. 164, No. 1 (March 2012): pg. 7-14. DOI. This article is (C) Elsevier and permission has been granted for this version to appear in e-Publications@Marquette. Elsevier does not grant permission for this article to be further copied/distributed or hosted elsewhere without the express permission from Elsevier. 
of the main motivations for using in-plane rather than out-of-plane flexural modes.

While the piezoresistive detection of the first out-of-plane mode is - especially in liquid - difficult using the devices studied in this work (the piezoresistors are intentionally positioned such that signals stemming from out-of-plane flexural modes are suppressed), a small peak associated with the out-of-plane mode could be observed in liquid for some of the devices. Analyzing this data showed frequency changes on the order of $30-50 \%$ for the first out-of-plane mode in water relative to their value in air. These values were confirmed through optical measurements performed with a Polytec MSA-500 analyzer that is able to measure in- and out-of-plane vibration amplitudes: for a $400 \mu \mathrm{m}$ long, $90 \mu \mathrm{m}$ wide and $20 \mu \mathrm{m}$ thick cantilever, the optically detected first out-of-plane mode shifted from $154.6 \mathrm{kHz}(Q=680)$ to $96.1 \mathrm{kHz}(Q=20)$, i.e., by $38 \%$ when going from air to water. For the same $400 \mu \mathrm{m}$ long, $90 \mu \mathrm{m}$ wide and $20 \mu \mathrm{m}$ thick cantilever, the frequency of the first in-plane flexural mode decreased from $636.7 \mathrm{kHz}$ to $596.0 \mathrm{kHz}$, i.e., a shift of only $7 \%$. Among all tested cantilever dimensions, the smallest observed frequency shifts are less than $4 \%$ when immersing the cantilever from air into water ( Fig. 5).

\section{Sensor design tradeoffs}

The quality factor and frequency change due to mass loading in liquid do not, however, give the entire picture when it comes to fabricating effective resonant sensors. As shown above (Eq. (1)), the limit of detection for closed-loop operation is a function of both the short-term frequency stability (which is correlated with the resonator quality factor) and the sensor sensitivity. The chemical sensitivity is the product of the gravimetric sensitivity $G$ and the analyte sensitivity $S_{A}$, the latter depending only on the sorption characteristics of the sensitive layer (polymer or ligand). The gravimetric sensitivity $G$ of the cantilevers has been simulated using the finite element software COMSOL (Stockholm, Sweden). Using modal analyses, the in-plane resonance frequencies of cantilevers with different dimensions coated with a $2 \mu \mathrm{m}$ polymer layer (density of $840 \mathrm{~kg} / \mathrm{m}^{3}$ ) have been obtained and the gravimetric sensitivity was extracted (see Fig. 8) by changing the polymer density. It should be noted that the thermal oxide and 
PECVD passivation layers were not included in the simulations, nor were the effects of the surrounding fluid. The stiffness of the polymer layer was assumed to be negligible compared to that of the silicon for the simulations.

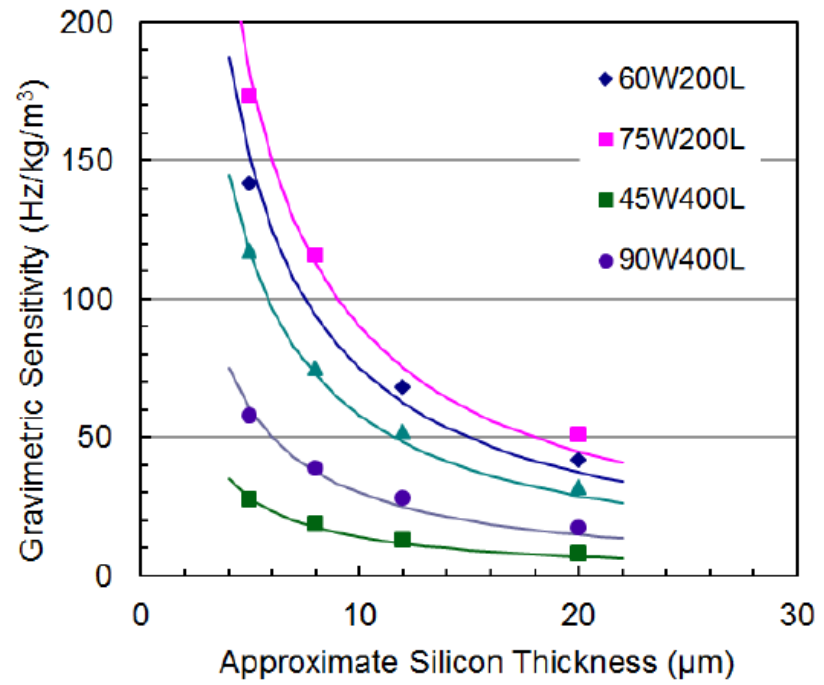

Figure 8: The gravimetric sensitivity of coated cantilevers as a function of the silicon thickness for $200 \mathrm{~m}$ and $400 \mathrm{~m}$ long beams with different widths. The cantilevers are coated with a $2 \mu \mathrm{m}$ thick polymer film with a density of $840 \mathrm{~kg} / \mathrm{m} 3$. The gravimetric sensitivity of the devices was extracted from modal analyses performed using the finite element software COMSOL. The key in the upper right hand corner gives the size of the cantilever associated with each set of datapoints i.e. $60 \mathrm{~W} 200 \mathrm{~L}$ indicates a $60 \mu \mathrm{m}$ wide by $200 \mu \mathrm{m}$ long cantilever.

The simulations show that shorter, wider and thinner beams yield the highest gravimetric sensitivities. At the same time, shorter and wider cantilevers (i.e., those with higher in-plane resonance frequency) offer a higher quality-factor and lower frequency shift when immersed into water (indicating less mass-loading by the surrounding fluid). It should be noted that the relative gravimetric sensitivity $G_{R}$ for the in-plane mode, i.e., the frequency shift per unit change in coating density, normalized by the resonant frequency, is only a function of the thickness of the layers comprising the beam's cross-section (assuming a uniform cross section for all the beams being compared) [27]. Thus, for the beams tested, the thinner cantilevers will give a larger relative frequency drop for the same mass loading, i.e., the thinner beams will ultimately offer higher sensitivity than thicker ones (when comparing cantilevers of the same length and width). 
For the chemical resolution, however, the frequency stability has to be considered as well: experimental data (Fig. 4) shows that making the cantilevers thinner will degrade $Q$, which can have a large effect on the frequency stability and thus resolution. For example, a $45 \mu \mathrm{m}$ wide, $200 \mu \mathrm{m}$ long cantilever with a measured $Q=36$ showed a short-term frequency stability of $2.9 \mathrm{~Hz}$, while a $45 \mu \mathrm{m}$ wide, $800 \mu \mathrm{m}$ long cantilever $(Q=9.6)$ has a short-term frequency stability of approximately $70 \mathrm{~Hz}$. The short-term frequency stabilities were measured using the Allan Variance method [28] at a gate time of $1 \mathrm{~s}$. A general guideline from our experimental data is that a $Q$ of at least 25-35 is required for stable closed-loop operation in water. Among the tested cantilevers, the $200 \mu \mathrm{m}$ long devices showed the highest $Q$ in liquid; the measured quality factor plotted as a function of the silicon thickness for the three different widths of the $200 \mu \mathrm{m}$-long cantilevers is presented in Fig. 9. It can be seen that $Q$-factors above 30 are achieved for thicknesses $>5 \mu \mathrm{m}$, making $200 \mu \mathrm{m}$ long cantilevers with a thickness between 5 and $10 \mu \mathrm{m}$ a good choice for liquid-phase sensing. Cantilevers with a thickness greater than $10 \mu \mathrm{m}$ have a lower gravimetric sensitivity than their thinner counterparts and are a less optimal choice for liquid-phase sensing.

When considering the length and width dimensions, it appears that the shortest and widest cantilevers are best for sensor applications using the in-plane mode, i.e., a $75 \mu \mathrm{m} \times 200 \mu \mathrm{m}$ cantilever would be preferred for liquid-phase sensing (see Fig. 4 and Fig. 5). However, the higher stiffness of shorter and wider beams, which is responsible in large part for their higher $Q$ and frequency values, has its negative aspects as well: since all of the excitation resistors have the same resistance, each will dissipate the same amount of power as heat for the same heating voltage, and thus apply the same amount of bending force. Therefore, the wider and shorter beams (which have a higher stiffness) exhibit smaller vibration amplitudes when excited. These smaller amplitudes may make closedloop operation far more difficult, if not impossible, for excessively stiff designs. 


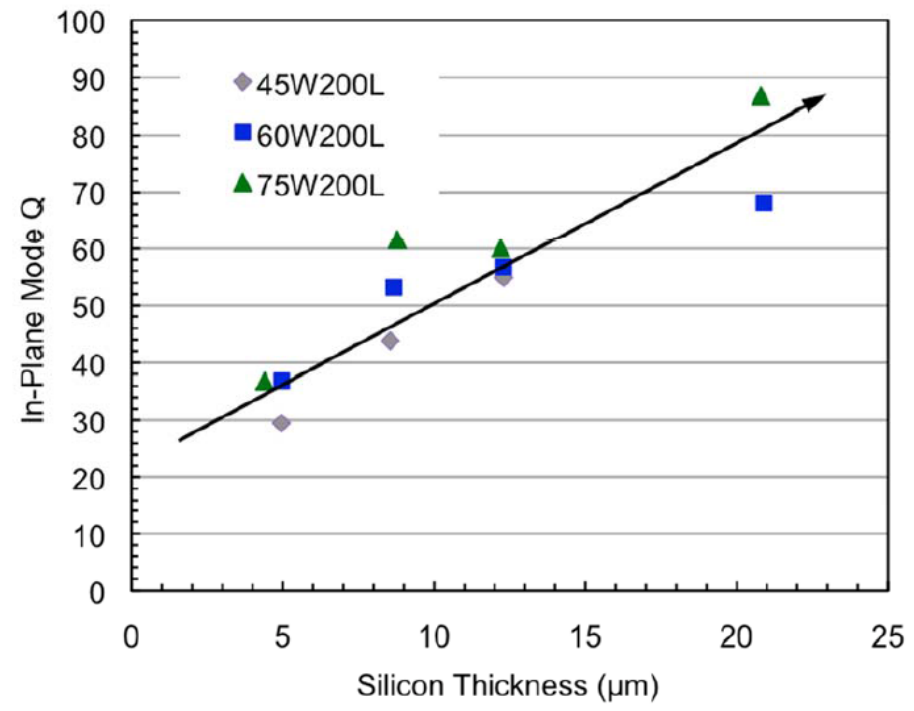

Figure 9: Quality factor as a function of silicon thickness for $200 \mu \mathrm{m}$ long cantilevers operated in water. The key in the upper left hand corner gives the size of the cantilever associated with each set of points i.e. $45 \mathrm{~W} 200 \mathrm{~L}$ indicates a $45 \mu \mathrm{m}$ wide by $200 \mu \mathrm{m}$ long cantilever.

Higher heating powers could be used in order to excite stiffer cantilevers, yet this is undesirable for two reasons: (1) higher heating power would increase the power consumption of the devices, which is undesirable for in situ applications; (2) the temperature increase along the length of the cantilever is problematic for (bio)chemical sensing applications because high temperatures can denature proteins and lower the partition coefficients of analytes in polymers used for chemical sensing. COMSOL (Stockholm, Sweden) simulations based on the currently used $1.5 \mathrm{~V}_{\mathrm{pp}} \mathrm{AC}$ excitation and $\pm 3 \mathrm{~V}$ DC biases show a maximum temperature rise of $\approx 10^{\circ} \mathrm{C}$ above room temperature on the cantilever surface.

\section{Conclusions}

Twenty different cantilever length and width combinations were tested in water for the purpose of determining their resonant properties using their first in-plane flexural mode and their potential for liquid-phase biochemical sensing applications utilizing this mode. For each of the length/width combinations, up to four different silicon thicknesses were tested. Using the measured characterization data 
and considering resonant sensor design objectives, it was determined that the shorter, wider and thinner beams give the best sensing characteristics. Of the cantilevers tested here, the ones most promising for sensing applications are those having resonant frequencies in the $700-1200 \mathrm{kHz}$ range, as evidenced by their combination of high quality factor and sensitivity, while exhibiting sufficiently low stiffness so that they could be excited thermally in liquid. In terms of thickness, the $5 \mu \mathrm{m}$ and $8 \mu \mathrm{m}$ thick beams demonstrated the greatest potential for sensing; however, one must ensure that the chosen device has a sufficiently large $Q$ for stable closed-loop operation. Theoretical and experimental results indicate that, of the cantilevers tested, $45 \mu \mathrm{m}$ wide, $200 \mu \mathrm{m}$ long devices with $5 \mu \mathrm{m}$ or $8 \mu \mathrm{m}$ thicknesses should yield the best compromise and the lowest limits of detection.

Compared to other studies of liquid-phase operation of singlecrystal silicon resonators, the achieved quality factors from this work are a factor of 3-4 times higher than most of those previously published. An exception are the high $Q$-factors in water achieved in [16], which however come at the expense of higher power consumption and larger temperature rise along the surface. The temperature rise on the device surface would denature ligands used for biosensing making these devices problematic for biochemical sensor applications. For the cantilevers investigated here further improvements are possible, including testing other cantilever geometries that have resonant frequencies in the $700-1200 \mathrm{kHz}$ range.

\section{Acknowledgements}

The authors would like to thank the Georgia Institute of Technology Nanotechnology Research Center staff for fabrication support. This work was supported in part by the National Science Foundation under award number ECCS-0824017.

\section{References}

1. Brand, O., Microsensor Integration Intro Systems-on-Chip. Proceedings of the IEEE. 94(6): p. 1160-1176.

Sensors and Actuators B: Chemical, Vol. 164, No. 1 (March 2012): pg. 7-14. DOI. This article is (C) Elsevier and permission has been granted for this version to appear in e-Publications@Marquette. Elsevier does not grant permission for this article to be further copied/distributed or hosted elsewhere without the express permission from Elsevier. 
NOT THE PUBLISHED VERSION; this is the author's final, peer-reviewed manuscript. The published version may be accessed by following the link in the citation at the bottom of the page.

2. Vancura, C., et al., Liquid-phase chemical and biological detection using fully integrated magnetically actuated complementary metal oxide semiconductor resonant cantilever sensor systems. Analytical Chemistry. 79(4): p. 1646-1654.

3. Waggoner, P.S. and H.G. Craighead, Micro- and nanomechanical sensors for environmental, chemical, and biological detection. Lab Chip. 7(10): p. $1238-1255$.

4. Naeli, K. and O. Brand, Dimensional Considerations in Achieving Large Quality Factors for Resonant Silicon Cantilevers in Air. Journal of Applied Physics. 105(1): p. 014908.

5. Lu, J., et al., Mechanical Quality Factor of Cantilevers for Mass Sensing Applications. Proceedings of SPIE. 6800: p. 68001Y-1-668001Y07.

6. Chandorkar, S.A., et al., Multimode Thermoelastic Dissapation. Journal of Applied Physics. 105(4): p. 043505.

7. Cox, R., et al., Generalized Model of Resonant Polymer-Coated Microcantilevers in Viscous Liquid Medium. Analytical Chemistry. 80(15): p. 5760-5767

8. Lochon, F., I. Dufour, and D. Rebiere, A microcantilever chemical sensors optimization by taking into account losses. Sensors and Actuators B: Chemical, 2006. 118: p. 292-296.

9. Li, X., et al., Integrated MEMS/NEMS Resonant Cantilevers for Ultrasensitive Biological Detection. Journal of Sensors, 2009.

10. Liu, Y., et al., Nanogram per milliliter-level immunologic detection of alpha-fetoprotein with integrated rotating-resonance microcantielvers for early-stage diagnosis of hetocellular carcinoma. Biomedical Microdevices, 2009. 11: p. 183-191.

11. Ricciardi, C., et al., Integration of microfluidic and cantilever technology for biosensing applications in liquid environment. Biosensors \& Bioelectronics, 2010. 26: p. 1565-1570.

12. Urey, H., et al. MEMS Biosensor for Parallel and Highly Sensitive and Specific Detection of Hepatitis. in 24th IEEE MEMS Conference. 2011. Cancun, Mexico.

13. Seo, J.H. and O. Brand, High Q-factor in-plane mode resonant mircrosensor platform for gaseous/liquid environment. Journal of Microelectromechanical Systems. 17(2): p. 483-493.

Sensors and Actuators B: Chemical, Vol. 164, No. 1 (March 2012): pg. 7-14. DOI. This article is (C) Elsevier and permission has been granted for this version to appear in e-Publications@Marquette. Elsevier does not grant permission for this article to be further copied/distributed or hosted elsewhere without the express permission from Elsevier. 
NOT THE PUBLISHED VERSION; this is the author's final, peer-reviewed manuscript. The published version may be accessed by following the link in the citation at the bottom of the page.

14. Toa, Y., et al., Resonant cantilever sensors operated in a high-Q in-plane mode for real-time bio/chemical detection in liquids. Sensors and Actuators B: Chemical, 2011. 157: p. 606-614.

15. Rahafrooz, A. and S. Pourkamali. Resonant MEMS sensors for detection of aqueous heavy metal ions with sub-ppm resolution. in 2008 IEEE International Conference on Electron Devices and Solid-State Circuits. 2008. Hong Kong, China: Inst. of Elec. and Elec. Eng. Computer Society.

16. Rahafrooz, A. and S. Pourkamali. Rotational Mode Disk Resonators for High-Q Operation in Liquid. in IEEE Sensors Conference. 2010. Waikoloa, Hawaii.

17. Cheney, C.P., et al., Ethanol vapor detection in saline solution using piezoresistive microcantilevers. Review of Scientific Instruments, 2006. 77(9): p. 95101-1.

18. Burg, T.P., et al., Weighing of biomolecules, single cells and nanoparticles in fluid. Nature. 446(7139): p. 11066-11069.

19. Lee, J., et al., Suspended Microchannel resonators with piezoresistive sensors. Lab on a Chip, 2011. 11: p. 645-651.

20. Agache, V., et al. Suspended Nanochannel in MEMS Plate Resonator for Mass Sensing in Liqudi. In 24th IEEE MEMS Conference. 2011. Cancun, Mexico.

21. Park, J., et al. Novel Type of Microcantilever Biosensor Resonating at the Interface Between Liquid and Air. in 24th IEEE MEMS Conference. 2011. Cancun, Mexico.

22. Lange, D., et al., Complementary metal oxide semiconductor cantilever arrays on a single chip: masssensitive detection of volatile organic compounds. Analytical Chemistry. 74(13): p. 3084-3095.

23. Beardslee, L.A., et al., Thermal Excitation and Piezoresistive Detection of Cantilever In-Plane Resonance Modes for Sensing Applications. Journal of Microelectromechanical Systems, 2010. 19(4): p. 1015-1017.

24. Seo, J.H., Silicon-Based Resonant Microsensor Platform for Chemical and Biological Applications, in Electrical and Computer Engineering2007, Georgia Institute of Technology: Atlanta. p. 192.

25. Heinrich, S.M., et al. An Analytical Model of a Thermally Excited Microcantilever Vibrating Laterally in a Viscous Fluid. in Proceedings of the IEEE Sensors Conference. 2010. Waikoloa, Hawaii.

Sensors and Actuators B: Chemical, Vol. 164, No. 1 (March 2012): pg. 7-14. DOI. This article is (C) Elsevier and permission has been granted for this version to appear in e-Publications@Marquette. Elsevier does not grant permission for this article to be further copied/distributed or hosted elsewhere without the express permission from Elsevier. 
NOT THE PUBLISHED VERSION; this is the author's final, peer-reviewed manuscript. The published version may be accessed by following the link in the citation at the bottom of the page.

26. Heinrich, S.M., et al., An Analytical Model for In-Plane Flexural Vibrations of Thin Cantilever-Based Sensors in Viscous Fluids: Applications to Chemical Sensing in Liquids, in Proceeding of the International Workshop on Nanomechanical Cantilever Sensors2010: Banff, Canada. p. FP5.

27. Beardslee, L.A., et al., On the Relative Sensitivity of Mass-Sensitive Chemical Microsensors, in To Be Presented at and Published in the Proceedings of Transducers2011: Beijing, China.

28. Allan, D.W. and J.A. Barnes. A Modified Allan Variance with Increased Oscillator Characterization Ability. in 35th Annual Frequency Control Symposium. 1981. Philadelphia.

\section{About the Authors}
L.A. Beardslee
: Department of Electrical and Computer Engineering, Georgia Institute of Technology, Atlanta, GA, USA
Email: beardsl@mail.amc.edu
Vitae: Luke A. Beardslee received a BS and Master of Engineering in Electrical Engineering from Cornell University in 2006 and 2007, and a PhD in Electrical Engineering from the Georgia Institute of Technology in 2011. He is currently pursuing an MD degree at Albany Medical College in Albany, NY. His research interests include the application of micro/nanotechnology to biomedical problems, in particular biosensors and implantable devices.

Fabien Josse

: Department of Electrical and Computer Engineering, Marquette University, Milwaukee, WI, USA

Vitae: Fabien Josse received the License de Mathematics et Physique in 1976, the MS and $\mathrm{PhD}$ degrees in Electrical Engineering from the University of Maine in 1979 and 1982, respectively. He has been with Marquette University, Milwaukee, WI, since 1982 and is currently professor in the Department of Electrical and Computer Engineering, and the Department of Biomedical Engineering. His research interests include solid state sensors, 
NOT THE PUBLISHED VERSION; this is the author's final, peer-reviewed manuscript. The published version may be accessed by following the link in the citation at the bottom of the page.

acoustic wave sensors and MEMS devices for liquid-phase bio-chemical sensor applications, investigation of novel sensor platforms, and smart sensor systems. Prof. Josse is a senior member of IEEE.

Stephen M. Heinrich: Department of Civil and Environmental Engineering, Marquette University, Milwaukee, WI, USA

Vitae: Stephen M. Heinrich earned his BS from Penn State in 1980 and his MS and PhD degrees from the University of Illinois in 1982 and 1985, all in civil engineering. He then joined the faculty at Marquette University where he is currently Professor of Civil Engineering. Dr. Heinrich's research has focused on structural mechanics applications in microelectronics packaging and the development of new analytical models for predicting/enhancing the performance of cantilever-based chemical sensors. The work performed by Dr. Heinrich and his colleagues has resulted in over 100 publications/presentations and three best-paper awards from IEEE and ASME.

Isabelle Dufour : Université de Bordeaux, IMS, Talence, France

Vitae: Isabelle Dufour graduated from

EcoleNormaleSupérieure de Cachan in 1990 and received the PhD and HDR degrees in Engineering Science from the University of Paris-Sud, Orsay, France, in 1993 and 2000, respectively. She was a CNRS research fellow from 1994 to 2007, first in Cachan working on the modelling of electrostatic actuators (micromotors, micropumps) and then after 2000 in Bordeaux working on microcantileverbased chemical sensors. She is currently Professor of electrical engineering at the University of Bordeaux and her research interests are in the areas of microcantileverbased sensors for chemical detection, rheological measurements and materials characterisation.

Sensors and Actuators B: Chemical, Vol. 164, No. 1 (March 2012): pg. 7-14. DOI. This article is (C) Elsevier and permission has been granted for this version to appear in e-Publications@Marquette. Elsevier does not grant permission for this article to be further copied/distributed or hosted elsewhere without the express permission from Elsevier. 
NOT THE PUBLISHED VERSION; this is the author's final, peer-reviewed manuscript. The published version may be accessed by following the link in the citation at the bottom of the page.

Oliver Brand : Department of Electrical and Computer Engineering, Georgia Institute of Technology, Atlanta, GA, USA

Vitae: Oliver Brand received his diploma degree in Physics from Technical University Karlsruhe, Germany in 1990, and his PhD degree from ETH Zurich, Switzerland in 1994. From 1995 to 1997, he worked as a postdoctoral fellow at Georgia Tech. From 1997 to 2002, he was a lecturer at ETH Zurich, Switzerland and deputy director of the Physical Electronics Laboratory. In 2003, he joined the Electrical and Computer Engineering faculty at Georgia Institute of Technology where he is currently Professor. He has co-authored more than 150 publications in scientific journals and conference proceedings. $\mathrm{He}$ is a co-editor of the Wiley-VCH book series Advanced Micro and Nanosystems, a member of the editorial board of Sensors and Materials, and has served as General Co-Chair of the 2008 IEEE International Conference on Micro Electro Mechanical Systems (MEMS 2008). Dr. Brand is a senior member of the IEEE and a corecipient the 2005 IEEE Donald G. Fink Prize Paper Award. His research interests are in the areas of silicon-based microsystems, microsensors, MEMS fabrication technologies, and microsystem packaging. 